\title{
Effect of $\beta 3$-adrenoceptor on cardiac fibrosis in rat cardiac fibroblast cells and its potential mechanism
}

\author{
Yuan Zhang ${ }^{1}$, Hui Zhang ${ }^{1}$, Yitong $\mathrm{Ma}^{2}$, Yining Yang ${ }^{2}$, Miaomiao Ma ${ }^{1}$, Xiaoli Zhu ${ }^{1}$ \\ and Li Wang ${ }^{1 *}$ \\ ${ }^{1}$ The 2nd Department of Cardiology, The First Affiliated Hospital of the Medical College, Shihezi University, Shihezi, 832008, \\ ${ }^{2}$ Heart Centre, The First Affiliated Hospital of Xinjiang Medical University, Wulumuqi, 830011, PR China
}

*For correspondence: Email: wanglishz@163.com; Tel: +86-0993-2858754

Received: 21 October 2015

Revised accepted: 13 March 2016

\begin{abstract}
Purpose: To investigate the effect of $\beta 3$-adrenoceptors ( $\beta 3-A R)$ up-regulation on fibrosis in cardiac fibroblast cells in rats and its potential mechanism.

Methods: Cardiac fibroblast cells (CFB) were isolated and identified from rats' hearts. The $\beta 3-A R u p-$ regulated cardiac fibroblast cells were constructed by lentiviral transfection technology. Thereafter, Ang II was used to induce fibrosis in cardiac fibroblast cells, and subsequently, Western blot assay was performed to investigate fibrosis related marker proteins (TGF- $\beta$, Smad-2, $p$-Smad-2, Col-I and Col-III) in cardiac fibroblast cells.

Results: $\beta 3-A R$ up-regulated cardiac fibroblast cells were successfully constructed. Furthermore, the results show that up-regulation of $\beta 3-A R$ increased the expressions of TGF- $\beta, p-S m a d-2, C o l-I$ and ColIII proteins in Ang II treated cardiac fibroblast cells.

Conclusion: The results suggest that up-regulation of $\beta 3-A R$ aggravates fibrosis of cardiac fibroblast cells. In other words, inhibition of $\beta 3-A R$ expressions in cardiac tissues would be beneficial for treating cardiac fibrosis and its related cardiac diseases.
\end{abstract}

Keywords: Cardiac fibrosis, $\beta 3-A R$, TGF/Smads, Col-I/III, Cardiac fibroblast cells

Tropical Journal of Pharmaceutical Research is indexed by Science Citation Index (SciSearch), Scopus, International Pharmaceutical Abstract, Chemical Abstracts, Embase, Index Copernicus, EBSCO, African Index Medicus, JournalSeek, Journal Citation Reports/Science Edition, Directory of Open Access Journals (DOAJ), African Journal Online, Bioline International, Open-J-Gate and Pharmacy Abstracts

\section{INTRODUCTION}

Cardiovascular disease is one of the leading causes of death all over the world [1]. Cardiac fibrosis is characterized by excessive deposition of collagenous fiber in the extracellular matrix (ECM) and disproportionate increase and disordered arrangement of myocardial collagen [2-4]. Increasing evidence demonstrated that cardiac fibrosis (CF) is a central factor for the development of several serious cardiovascular diseases, including cardiac failure, myocardial infarction and cardiac hypertrophy, etc [2,4-6]. Therefore, discovering more novel reliable cardiac fibrosis interventions might be a feasible approach to cure various serious heart diseases.

Previous investigations revealed that $\beta 3$ Adrenoceptors ( $\beta 3-A R$ ) is lowly expressed in normal human and animal ventricle myocardium, and the activation of $\beta 3-A R$ could affect myocardial contraction and plays an important role in the pathogenesis of cardiac dysfunction [7-9]. However, so far, there is no reported work regarding the effects of $\beta 3-A R$ on cardiac fibrosis, thus our present study is designed to investigate the potential of $\beta 3-A R$ on fibrosis in cardiac fibroblast cell and its potential 
mechanism. In our present work, $\beta 3$-AR overregulated cardiac fibroblast cells were constructed by lentiviral transfection. Then, Ang II was used to induce fibrosis in the cardiac fibroblast cell, and subsequently western blot assay was performed to investigate the fibrosis related marker proteins in the cardiac fibroblast cells.

\section{EXPERIMENTAL}

\section{Animals}

SD sucking rats ( 1 - 3 days), purchased from the experimental animal center of the first affiliated hospital of Xinjiang Medical University (Urumqi, China), were used in the present investigation. The protocol for the use of animals was according to the guidelines of animal experiments from the ethical committee for animal research of the First Affiliated Hospital of the Medical College, Shihezi University (ethical approval o.: S2013-04-02).

\section{Reagents and chemicals}

The resulting recombinant lenti viruses (Objective gene sequence number: NM_013108.2) were purchased from Cyagen Biosciences Inc., (Guangzhou, China). DMEM medium and fetal bovine serum (FBS) were purchased from Gibco Co. (Shanghai, China); B3-ARprimary antibody was purchased from
Santcruz Co. (Japan), TGF- $\beta$ and Collagen-III (Col-III) primary antibodies were purchased from Protein tech Co. (USA), Smad-2/3, PhosphoSmad-2,vimentin, horseradish- peroxidaseconjugated secondary antibodies and GAPDH primary antibodies were purchased from Cell Signaling Co. (USA), Col-III primary antibody was purchased from Abcam (UK); BCA protein assay kit was purchased from Beyotime (Jiangsu, China). All other regents and chemical used in our present study were analytical grade.

\section{Primary culture of rat ventricular cardiac fibroblasts}

Rat cardiac fibroblasts were isolated and cultured according to previously described method [4]. Briefly, hearts of the rats were removed and chopped into $1 \mathrm{~mm}^{3}$ pieces, then digested in 0.1 $\%$ type II collagenase and $0.25 \%$ trypsin. Subsequently, the cell suspension was centrifuged to collect the cell pellet, then the cell pellet was re-suspended with DMEM containing $10 \%$ FBS. After $1 \mathrm{~h}$ incubation in culture flask, the attached cells were further cultured at $37^{\circ} \mathrm{C}$ in a humidified and $5 \% \mathrm{CO}_{2}$ atmosphere. The isolated cardiac fibroblasts were identified by using the immunofluorescence assay with vimentin protein, and our results showed that the vimentin protein positive cells accounted for more than $95 \%$ (Figure 1). The second to fourth passages of cardiac fibroblasts were used for our research.

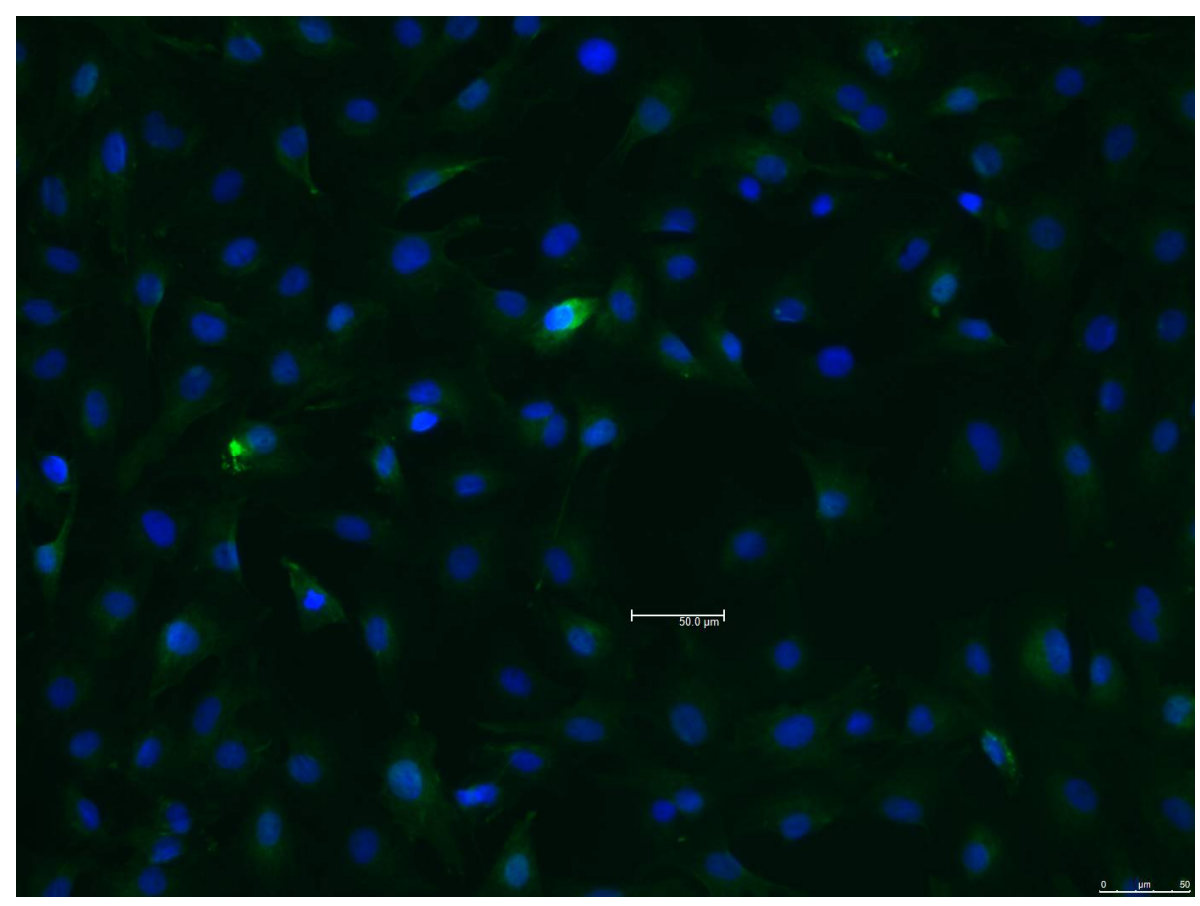

Figure 1: Identification of the isolated cardiac fibroblasts using immunofluorescence assay. Cells were stained with DAPI and anti-vimentin antibody, and the blue fluorescence represented the nucleus and green fluorescence represented the vimentin proteins 


\section{Preparation of $\beta 3-A R$ up-regulated cardiac fibroblast cells}

The $\beta 3-A R$ gene siRNA vector recombinant plasmid was constructed using RNA interference technique. Then the resulting recombinant lentiviruses were used to infect cardiac fibroblast cells to up-regulate the $\beta 3-A R$. The expression of $\beta 3-A R$ in normal cardiac fibroblast cells (N-CFC), cardiac fibroblasts cells with $\beta 3-A R$ up-regulation (CFC- $\beta 3-A R$ ), and cardiac fibroblast cells treated with control vector (EC) were detected using western blotting and fluorescence microscope observation. In addition, flow cytometry assay was performed to determine the transfection rate.

\section{Western blot}

After lentiviral transfection, the cardiac fibroblast cells were induced to fibrosis by treating with Ang II $\left(10^{-6} \mathrm{M}\right)$ for $24 \mathrm{~h}[4,10]$. Then, the cardiac fibroblast cells were cultured for extraction of total proteins. Subsequently, the protein concentration was determined using the BCA Protein Assay kit. Then equal amounts of proteins $(35 \mu \mathrm{g})$ were separated by SDS/PAGE, blotted on PVDF membrane and probed with various primary antibodies (including $\beta 3-A R$, TGF- $\beta$, Smad-2, Col-I and Col-III), followed by incubation with the secondary antibodies and chemiluminescence detection. To normalize for protein loading, antibodies directed against GAPDH were used.

\section{Statistical analysis}

Data are expressed as mean \pm SD of three independent experiments. Statistical analysis was carried out using SPSS 15.0 software package and one way analysis of variance (ANOVA) with Dunnett's test to compare the means between two groups with a significance level of $p<0.05$.

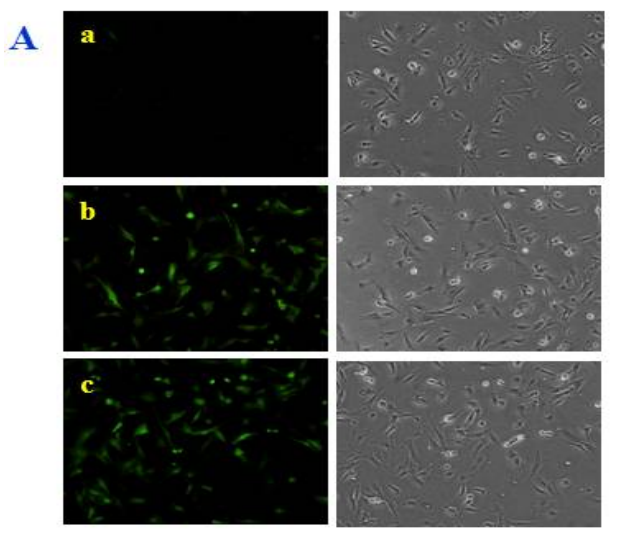

Figure 2: Results of the transfection. A. Results of the fluorescence microscope assay, a-c represent the normal cardiac fibroblast cells, cardiac fibroblast cells with $\beta 3$-AR up-regulation, and cardiac fibroblast cells treated with control vector, respectively. B. Results of the flow cytometry assay

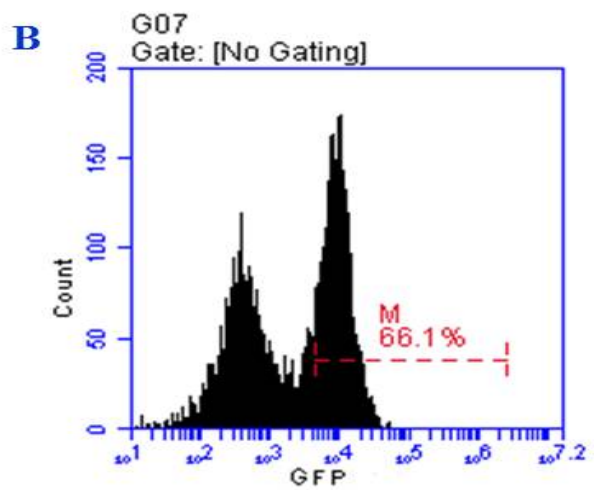

\section{Expression of $\beta 3-A R$ in cardiac fibroblast cells after transfection}

As can be seen from our results of fluorescence microscope assay which is shown in Figure 2A, after transfection, the $\beta 3-A R$ proteins were significantly up-regulated in the cardiac fibroblast cells, compared with both the N-CFC and EC groups, and the results of the flow cytometry assay showed that the transfection rate was nearly $70 \%$. Furthermore, the western blot results also indicated that $\beta 3-A R$ proteins expressions increased after transfection (Figure $3)$. These results suggest that the cardiac fibroblast cells with $\beta 3-A R$ up-regulation were constructed successfully.

\section{Effect of $\beta 3-A R$ up-regulation}

After being induced by Ang II for 24 h, TGF- $\beta$, Smad-2, Col-I and Col-III expressions in cardiac fibroblast cells were determined by western blotting assay. As can be seen from Figure 4, our results showed that no change was observed for Smad-2 expressions among all the test groups. However, it is interesting that TGF-ßand p-Smad2 were significantly up-regulated in $\beta 3-A R$ upregulated cardiac fibroblast cells, compared with the N-CFC, Agll-EC and Ag II-CFC. Furthermore, the collagen types I and III proteins (Col-I and III) were also determined in our present study, and our results revealed that both Col-I and Col-III were up-regulated in cardiac fibroblast cells by up regulation of the $\beta 3-A R$ (Figure 5 ). These results indicate that up-regulation of $\beta 3-A R$ could promote cardiac fibrosis in cardiac fibroblast cells.

Trop J Pharm Res, April 2016; 15(4): 719 


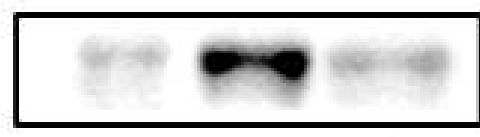

B3-AR

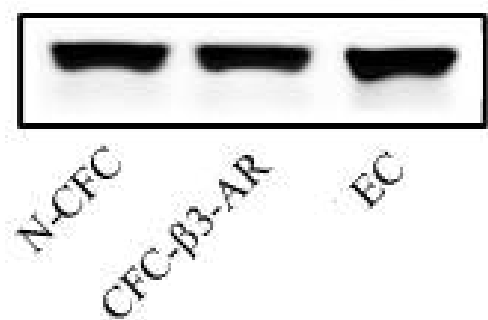

GAPDH

Figure 3: Expression of $\beta 3-A R$ in cardiac fibroblast cells after transfection. Protein expressions of $\beta 3-A R$ were determined by western blotting. N-CFC means the normal cardiac fibroblast cells CFC- $\beta 3-A R$ means with $\beta 3-A R$ up-regulation, and EC means cardiac fibroblast cells treated with control vector
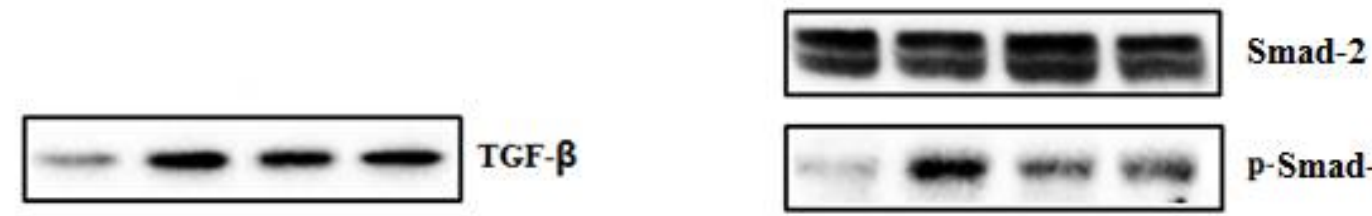

p-Smad-2

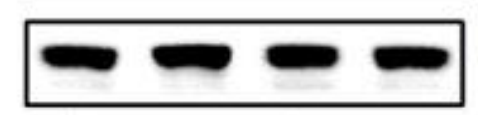

GAPDH

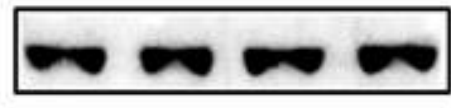

GAPDH
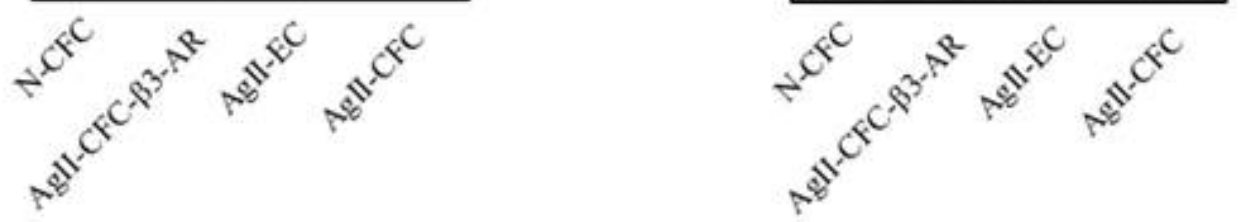

Figure 4: Results of expression of TGF- $\beta / \mathrm{Smad}-2$. Protein expressions were determined by western blotting. NCFC means the normal cardiac fibroblast cells (CFC), Agll-CFC- $\beta 3-A R$ means CFC- $\beta 3$-ARtreated by Angll, and Agll-EC means EC treated by Angll
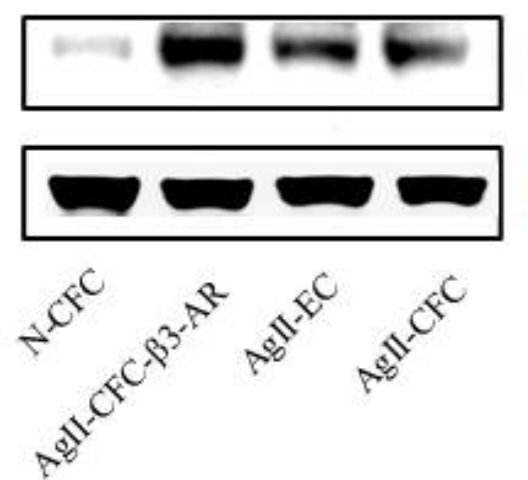

Col-I

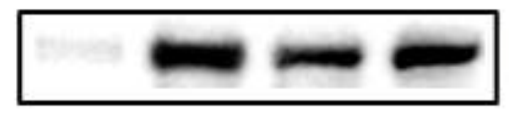

\section{GAPDH}

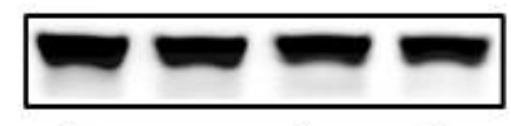

\section{GAPDH}

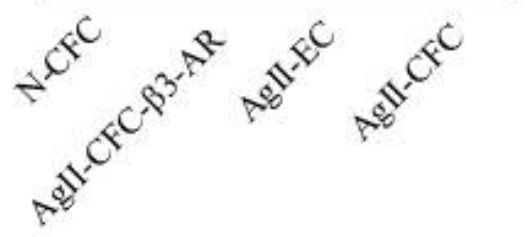

Col-III

Figure 5: Results of expression of Col-I/Col-III. Protein expressions were determined by western blotting. N-CFC means the normal cardiac fibroblast cells (CFC), Agll-CFC- $\beta 3-A R$ means CFC- $\beta 3-A R t r e a t e d$ by Angll, and AgllEC means EC treated by Angll

\section{DISCUSSION}

Tissue fibrosis can result in certain serious diseases for which effective therapy is lacking [11]. For the heart, cardiac fibrosis damages cardiac contraction and causes cardiac dysfunction [2]. Therefore, inhibition of cardiac fibrosis would be beneficial for improving some serious cardiac diseases. To the best of our knowledge, the present work is the first reported study on the effect of $\beta 3-A R$ on the development of cardiac fibrosis, which has significant reference value for the future treatment of cardiac diseases in the clinic. 
B3-AR is commonly expressed at low levels in cardiac tissues, and previous research revealed that $\beta 3-A R$ would be up-regulated in patients with dilated cardiomyopathy [8]. Therefore, we guessed that $\beta 3-A R$ might play an important role in the pathogenesis of cardiac fibrosis. In our study, the lentivirus transfection technology was used to construct the $\beta 3-A R$ over-expressed cardiac fibroblast cells. Previous reports have demonstrated that Ang II is a well-established factor related to many cardiac diseases and could induce the development of cardiac fibrosis $[12,13]$. Thus, Ang II induced cardiac fibrosis strategy is a commonly used experimental model both in vivo and in vitro $[4,14,15]$. In our present study, the fibrotic cardiac fibroblasts cells were induced successfully with Ang II. TGF- $\beta / S$ mads is a well-known pathway involved in multi-organ tissue fibrosis via inducing endothelialmesenchymal transition (EndMT) and vascular remodeling, etc. $[16,17]$. TGF- $\beta$ acts by activating Smads signaling pathway via phosphorylating the Smad-2/3 proteins. The $p$ Smads subsequently translocates from the cytoplasm into the nucleus to regulate other transcription factors $[18,19]$. Therefore, the expressions of TGF- $\beta /$ Smads could reflect the extent of cardiac fibrosis. Furthermore, collagen is the most abundant protein in animal tissues and also the major component in the interstitial extracellular matrix. Previous researches have revealed that Col-I and Col-III would be overexpressed in patients with cardiac fibrosis, and Col-I/III could be considered as the biomarkers of cardiac fibrosis [20,21]. In our present investigation, up-regulation of $\beta 3-A R$ increased the expressions of Col- I and Col- III. Both our results mentioned above suggested that upregulation of $\beta 3-A R$ aggravated the fibrosis of cardiac fibroblast cells. In other words, inhibition of $\beta 3-A R$ expression in cardiac tissues would be beneficial for treating cardiac fibrosis and its related cardiac diseases.

\section{CONCLUSION}

The findings of this work demonstrate that upregulation of $\beta 3-A R$ up-regulates the expressions of TGF- $\beta$, Smad-2, Col-I and Col-III in rat cardiac fibroblasts cells, thus suggesting that upregulation of $\beta 3-A R$ aggravates cardiac fibrosis. Thus, this present study also indicating that down-regulating $\beta 3-A R$ might be a useful strategy for treating cardiac fibrosis in clinic.

\section{ACKNOWLEDGEMENT}

This work was supported by National Natural Science Foundation of China (no. 81260028),
Development Program of Science and Technology Research, Team Innovation Item of Natural Science and Technological Innovation Foundation of Shihezi University (no. 2011ZRKXTD-07).

\section{REFERENCES}

1. Briet $M$, Boutouyrie $P$, Laurent $S$, London GM. Arterial stiffness and pulse pressure in CKD and ESRD. Kidney Int 2012; 82: 388-400.

2. Sirish P, Li N, Liu JY, Lee KS, Hwang SH, Qiu H, Zhao C, Ma SM, López JE, Hammock BD. Unique mechanistic insights into the beneficial effects of soluble epoxide hydrolase inhibitors in the prevention of cardiac fibrosis. Proc Natl Acad Sci USA 2013; 110: 5618-5623.

3. Gao SQ, Zhu PL. Research progress of myocardial fibrosis. Med Recapitul 2009; 15: 1627-1628.

4. Yu N, Jiang J, Yu Y, Li H, Huang X, Ma Y, Zhang L, Zou $J$, Zhang B, Chen S. SLC41A1 knockdown inhibits angiotensin II-induced cardiac fibrosis by preventing $\mathrm{Mg} 2+$ efflux and $\mathrm{Ca} 2+$ signaling in cardiac fibroblasts. Arch BiochemBiophys 2014; 564: 74-82.

5. Porter KE, Turner NA. Cardiac fibroblasts: At the heart of myocardial remodeling. Pharmacol Ther 2009; 123: 255278.

6. Liu Y, Hu ZF, Liao HH, Liu W, Liu J, Ma ZG, Wu QQ, Xu $M$, Zhang N, Zhang Y. Toll-like receptor 5 deficiency attenuates interstitial cardiac fibrosis and dysfunction induced by pressure overload by inhibiting inflammation and the endothelial-mesenchymal transition. Biochim Biophys Acta 2015; 1852: 2456-2466.

7. Montaudon E, Dubreil L, Lalanne V, Vermot Des Roches M, Toumaniantz G, Fusellier M, Desfontis JC, Martignat L. Mallem MY. Cardiac effects of long-term active immunization with the second extracellular loop of human $\beta 1$ - and/or $\beta 3$-adrenoceptors in Lewis rats. Pharmacol Res 2015; 100: 210-219.

8. Montaudon E, Abdelkrim MA, Desfonstis JC, Mallem Y. Cardiovascular effects of $\beta 1$ and $\beta 3$-adrenergic receptor autoantibodies in lewis rat. Ann Cardiol Angeiol 2014; 63: 128-134.

9. Niu X, Zhao L, Li X, XueY, Wang B. $\beta 3$-adrenoreceptor stimulation protects against myocardial infarction injuryvia eNOS and nNOS activation. PloS One 2014; 9: e98713.

10. Yu Y, Chen S, Xiao C, Jia Y, Guo J, Jiang J, Liu P. TRPM7 is involved in angiotensin II induced cardiac fibrosis development by mediating calcium and magnesium influx. Cell Calcium 2014; 55: 252-260.

11. Tao H, Shi KH, Yang JJ, Huang C, Liu LP, Li J. Epigenetic regulation of cardiac fibrosis. Cell Sign 2013; 25: $1932-1938$.

12. Zhang Z, Qu X, Ni Y, Zhang K, Dong Z, Yan X, Qin J, Sun $H$, Ding $Y$, Zhao $P$. Triptolide protects rat heart against pressure overload-induced cardiac fibrosis. Int $J$ Cardiol. 2013; 168: 2498-2505. 
13. Jiang $X$, Zhang $F$, Ning $Q$. Losartan reverses the downexpression of long noncoding RNA-NR024118 and Cdkn1c induced by angiotensin II in adult rat cardiac fibroblasts. Pathol Biol (Paris). 2015; 63: 122-125.

14. Duerrschmid C, Crawford JR, Reineke E, Taffet GE, Trial $J$, Entman ML, Haudek SB. TNF receptor 1 signaling is critically involved in mediating angiotensin-II-induced cardiac fibrosis. J Mol Cell Cardiol 2013; 57: 59-67.

15. Yang J, Zhu HH, Chen GP, Ye Y, Zhao CZ, Mou Y, Hu SJ. Inhibition of farnesyl pyrophosphate synthase attenuates angiotensin II-induced cardiac hypertrophy and fibrosis in vivo. Int $\mathrm{J}$ Biochem Cell Biol 2013; 45: 657-666.

16. Balta C, Herman H, Boldura OM, Gasca I, Rosu M, Ardelean A, Hermenean A. Chrysin attenuates liver fibrosis and hepatic stellate cell activation through TGF$\beta /$ Smad signaling pathway. Chem Biol Interact 2015; 240: 94-101.

17. Xin X, Li XH, Wu JZ, Chen KH, Liu Y, Nie CJ, Hu Y, Jin MW. Pentamethylquercetin ameliorates fibrosis in diabetic Goto-Kakizaki rat kidneys and mesangial cells with suppression of TGF- $\beta /$ Smads signaling. Eur $J$ Pharmacol. 2013; 713: 6-15.

18. Gaarenstroom T, Hill CS. TGF- $\beta$ signaling to chromatin: how Smads regulate transcription during self-renewal and differentiation. Semin Cell Dev Biol 2014; 32: 107118.

19. Yang KM, Kim W, Bae E, Gim J, Weist BM, Jung Y, Hyun JS, Hernandez JB, Leem SH, Park T. DRAK2 participates in a negative feedback loop to control TGF$\beta /$ Smads signaling by binding to type I TGF- $\beta$ receptor. Cell Rep 2012; 2: 1286-1299.

20. Hrckova G, Velebný $S$, Solár P. Dynamics of hepatic stellate cells, collagen types I and III synthesis and gene expression of selected cytokines during hepatic fibrogenesis following Mesocestoides vogae (Cestoda) infection in mice. Int J Parasitol. 2010; 40: 163-174.

21. Morita N, Mandel WJ, Kobayashi Y, Karagueuzian HS. Cardiac fibrosis as a determinant of ventricular tachyarrhythmias. J Arrhythm. 2014; 30: 389-394. 